\title{
Mortality Due to Aspergillosis in Wild Swans in Northwest Washington State, 2000-02
}

\author{
Marcy J. Souza, DVM, and Laurel A. Degernes, DVM, Dipl ABVP
}

\begin{abstract}
During the winters of 2000-01 and 2001-02, 400 trumpeter (Cygnus buccinator; $\mathrm{n}=$ 365 ) and tundra (Cygnus columbianus columbianus; $\mathrm{n}=35$ ) swans died in northwest Washington State. The carcasses were collected and frozen for necropsy, completed in May $2001(\mathrm{n}=172)$ and May $2002(\mathrm{n}=228)$. Although most swans died of lead poisoning, $64(16 \%)$ swans had gross pathologic lesions consistent with aspergillosis (trumpeter swan, $n=62$; tundra swan, $n=2$ ). Mild fungal infections consisted of small, nonobstructive lesions in the air sacs, trachea, or lungs, with lesions isolated to 1 area. Severe fungal infections consisted of large, extensive infiltrating lesions in the respiratory tract, with $68 \%$ of lesions in more than 1 area (lungs, air sacs, or trachea) and many with complete fibrinous casts within air sacs or trachea. Male swans were twice as likely as females to have fungal lesions, although there was no difference in the ratio of males and females with mild or severe infections. Juvenile swans ( $<1$ year of age) were twice as likely as adults and subadults to have fungal lesions and were also more likely to develop severe versus mild aspergillosis infections ( $\mathrm{n}=19, \mathrm{n}=1$, respectively). Although the number of swans with concurrent lead poisoning and aspergillosis was nearly $30 \%$ higher than that of swans with aspergillosis only, when compared with the total number of swans submitted for necropsy, swans with lead poisoning were $75 \%$ less likely to have fungal lesions than non-lead-poisoned swans, possibly because of rapid death from lead poisoning.
\end{abstract}

Key words: aspergillosis, fungal infection, lead poisoning, avian, waterfowl, Cygnus buccinator, trumpeter swans, tundra swans, Cygnus columbianus columbianus

\section{Introduction}

Spores of Aspergillus species are ubiquitous in our environment and are found on every continent. ${ }^{1}$ Environmental conditions favoring spore formation include decaying or wet food, bedding, and other organic material. ${ }^{1,2}$ Aspergillus infections are common in birds and have been described in numerous avian species. ${ }^{1-8}$ Development of avian aspergillosis is through inhalation of spores during feeding, nest building, and other activities in which the spores can be aerosolized. Lesions are usually localized in the respiratory system ${ }^{1-8}$ but may also be distributed to other organs, including kidneys and liver. ${ }^{9,10}$ Lesions have also been reported in the eyes and throughout the central nervous system, although these sites are uncommon. ${ }^{11}$ Granulomas of varying color (grey to yellow-green) and size are common. Aspergillus fumigatus is commonly reported in

From the Department of Clinical Sciences, College of Veterinary Medicine, North Carolina State University, 4700 Hillsborough Street, Raleigh, NC 27606-1428, USA. Present address (Souza): ABC Animal and Bird Clinic, 11930 Highway 6 South, Sugar Land, TX 77478, USA. Corresponding author: Dr Degernes. birds, but other species, including Aspergillus flavus, Aspergillus glaucus, and Aspergillus niger have also been reported. ${ }^{4}$

Reports of infection usually focus on captive or wild, recently captured animals. Few reports have examined the occurrence of aspergillosis in wild populations of birds. Aspergillosis was reported in $17 \%$ of trumpeter (Cygnus buccinator, $\mathrm{n}=21 / 115$ ) and tundra (Cygnus columbianus columbianus, $\mathrm{n}=$ 2/21) swans submitted for necropsy over a 6-year period in Washington state. ${ }^{12}$ Although infection rates for separate years in the 6-year period were not reported, the authors stated that a large number of the aspergillosis cases occurred in 1 year of the examined period, possibly because of contaminated feed. In a Minnesota study, aspergillosis was reported in $15.5 \%$ of trumpeter swans $(n=18 / 116)$ presented for necropsy over a $2^{1 / 2}$-year period..$^{13}$ In another recent study, 13 species of wild waterbirds in Spain were surveyed by immunodiffusion of serum samples to determine the prevalence of antibodies to Aspergillus. ${ }^{14}$ Results showed infection rates ranging from $0.9 \%-2.5 \%$ in 3 species of waterfowl tested (pochard [Aythya ferina], $\mathrm{n}=109$; 
Table 1. Distribution and severity of lesions in the respiratory tract of 63 wild swans with aspergillosis that died in Washington State during a 2-year period (2000-02).

\begin{tabular}{lccc}
\hline \hline \multicolumn{1}{c}{ Lesion distribution } & $\begin{array}{c}\text { Mild } \\
\text { aspergillosis } \\
(\mathrm{n}=13)\end{array}$ & $\begin{array}{c}\text { Severe } \\
\text { aspergillosis }^{\mathrm{a}} \\
(\mathrm{n}=50)\end{array}$ & $\begin{array}{c}\text { All swans with } \\
\text { aspergillosis }^{\mathrm{a}} \\
(\mathrm{N}=63)\end{array}$ \\
\hline Air sacs only & 5 & 8 & 13 \\
Trachea only & 7 & 5 & 12 \\
Lungs only & 1 & 3 & 4 \\
Lungs and air sacs & $-\mathrm{b}$ & 16 & 16 \\
Lungs, air sacs, and trachea & - & 3 & 12 \\
Lungs and trachea & - & 3 & 3 \\
Air sacs and trachea & - & 3 & 3 \\
\hline
\end{tabular}

${ }^{a}$ Lesion location was not reported for 1 swan with severe aspergillosis.

${ }^{\mathrm{b}}$ Multiple organs were unaffected in birds with mild aspergillosis.

mallard duck [Anas platyrhynchos], $\mathrm{n}=151$; greenwinged teal [Anas crecca], $\mathrm{n}=40$ ).

During the winters of 2000-01 and 2001-02, many trumpeter and tundra swans died in northwest Washington State. While most of these birds died of lead poisoning, many also had mild to severe fungal respiratory infection consistent with aspergillosis. The purpose of this study was to examine the distribution of pathologic lesions in swans that died and to determine possible risk factors associated with aspergillosis infections in swans, such as sex, age, and concurrent lead poisoning.

\section{Materials and Methods}

A total of 400 swan carcasses (trumpeter, $n=$ 365 ; tundra, $\mathrm{n}=35$ ) were collected over 2 winters (2000-01 and 2001-02). All necropsies were done in May $2001(\mathrm{n}=172)$ and May $2002(\mathrm{n}=228)$

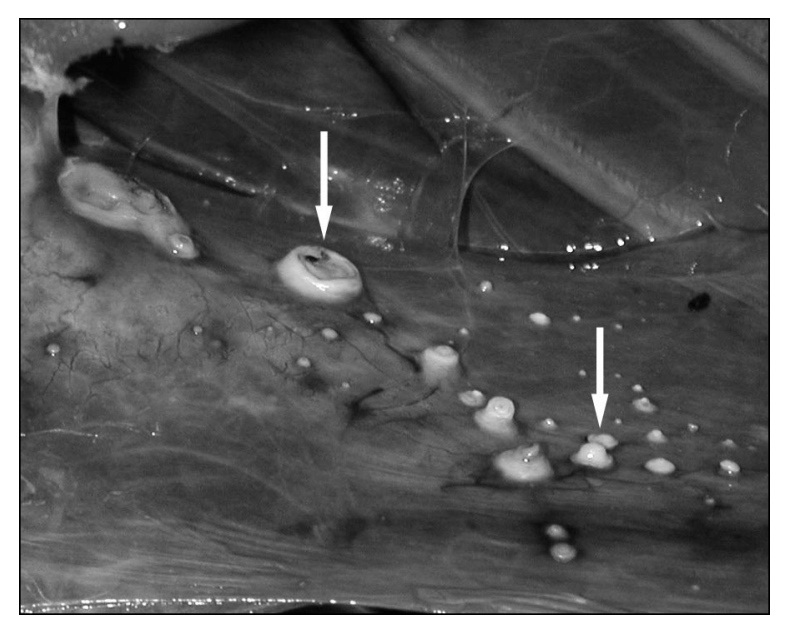

Figure 1. A wild trumpeter swan that died with lesions consistent with aspergillosis. Small, gray-green, umbilicated fungal granulomas are located throughout the left caudal thoracic air sac (arrows). by a team of veterinarians and veterinary students, with 1 veterinarian (L.A.D.) overseeing the evaluation of lesions. Cytologic examinations were performed on select cases to confirm the presence of fungal conidia; fungal cultures and histopathologic examinations were not performed. For each carcass, the sex, age category, lead-exposure status, and severity of fungal lesions were evaluated and recorded (Table 1). Clinical cases of lead poisoning were defined as those with lead levels in liver tissue greater than $20 \mathrm{ppm}$ dry weight (DW); those with tissue levels of 8-19.9 ppm DW in liver were categorized as subclinical; and those with $<8$ ppm DW were considered negative. ${ }^{15}$ Additional evidence of lead poisoning included the number of lead shot removed from the ventriculus and gross lesions consistent with lead poisoning (proventricular impaction, green liver, green-stained koilin lining of the ventriculus, and weight loss). ${ }^{16,17}$ Clinical and subclinical cases of lead poisoning were combined for analysis. For age, swans were categorized as juvenile ( $<1$ year of age), subadult (1-3 years of age), and adult ( $>3$ years of age). ${ }^{18}$ Adult and subadult swans were combined for analysis. Because of the small number of tundra swans $(n=2)$, tundra and trumpeter swans were combined for analysis.

For swans with aspergillosis, severity of infection was subjectively defined as mild or severe, based on the number, size, and distribution of fungal lesions observed grossly at necropsy. Mild infections were those where only a few small lesions (pinpoint to less than $1-\mathrm{cm}$ diameter) were located in the air sacs, trachea, or lungs (Table 1; Figs 1 and 2). Lung lesions were considered mild if lesions were walled off, smaller than $0.5-\mathrm{cm}$ diameter, or numbered less than 3. We assumed that mild aspergillosis lesions did not contribute to morbidity or mortality in affected birds. Severe infections were those where 


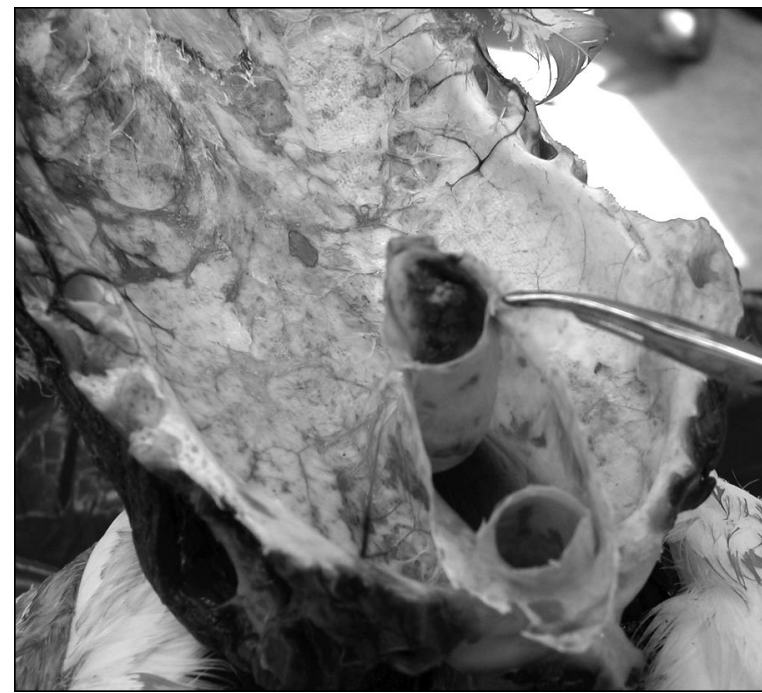

Figure 2. A trumpeter swan that died with lesions consistent with aspergillosis. The trachea is cut open, and a gray, nonobstructive fungal granuloma is located in the dorsal tracheal loop (see tip of the hemostat).

multiple lesions were present throughout the respiratory tract (Table 1). Lesions included numerous small white to gray granulomas throughout the lung parenchyma; large grey to yellow-green granulomas throughout the air sacs and trachea (Fig 3); and fibrinous casts within the trachea or air sacs (Fig 4). We assumed that severe aspergillosis lesions were associated with morbidity, mortality, or both in affected birds.

Data were analyzed for statistical significance by a commercially available software program (SigmaStat Statistical Software, Version 2.0, SPSS Inc, Chicago, IL, USA). Swans with and without aspergillosis were compared by sex, age category, and lead-exposure status. Severity of infection (mild versus severe) was also evaluated for association with each of these variables. A $\chi^{2}$ test was used to calculate odds ratios (OR) and $95 \%$ confidence intervals (CI) for compared groups. Fisher exact test was used when group numbers were less than 5 . Results were considered significant at $P<.05$.

\section{Results}

Gross lesions consistent with aspergillosis were found in 64 of 400 swans (16\%; 62 trumpeter and 2 tundra swans; Table 2). Lesions were located in the trachea, lungs, and air sacs; no gross fungal lesions were observed outside of the respiratory tract (Table 1). Of the 64 swans, 37 had concurrent aspergillosis and lead poisoning and 27 had aspergillosis only (liver lead levels were negative in 25 and

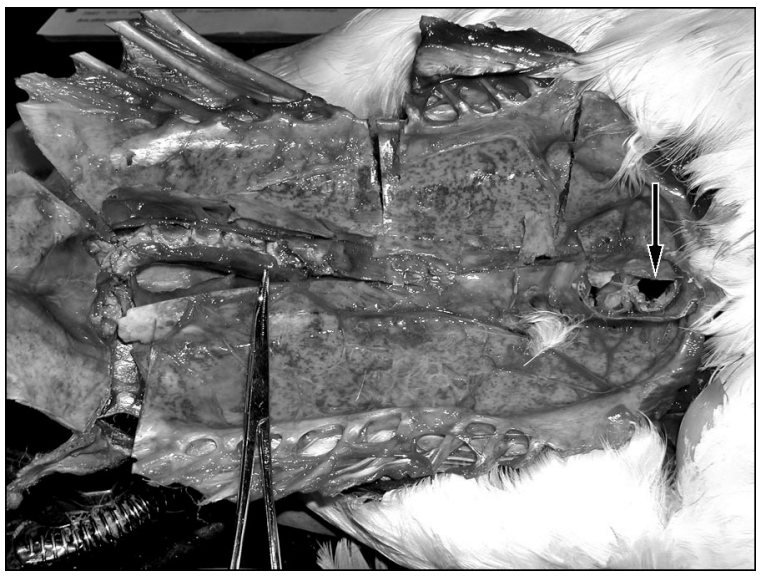

Figure 3. The dorsal surface of the keel in a trumpeter swan that died with lesions consistent with aspergillosis, showing both the caudal and dorsal loops of the trachea (see also Fig 5). A gray-green, fibrinous, obstructive fungal lesion fills the caudal loop of the trachea (portions of the keel and trachea have been cut away; see tip of hemostat). A smaller, gray fungal granuloma fills the dorsal loop of the trachea (trachea cut open; arrow).

were not documented in 2 swans with severe aspergillosis). In these 27 swans, aspergillosis was considered the cause of mortality. In the 37 swans with concurrent disease, the lack of antemortem clinical information precluded us from determining if aspergillosis or lead poisoning was the actual cause of death. Of the remaining 336 swans, 285 swans died of lead poisoning, 38 died from traumatic injuries (eg, powerline strikes, gunshot, etc) and 13 died of unknown or miscellaneous causes.

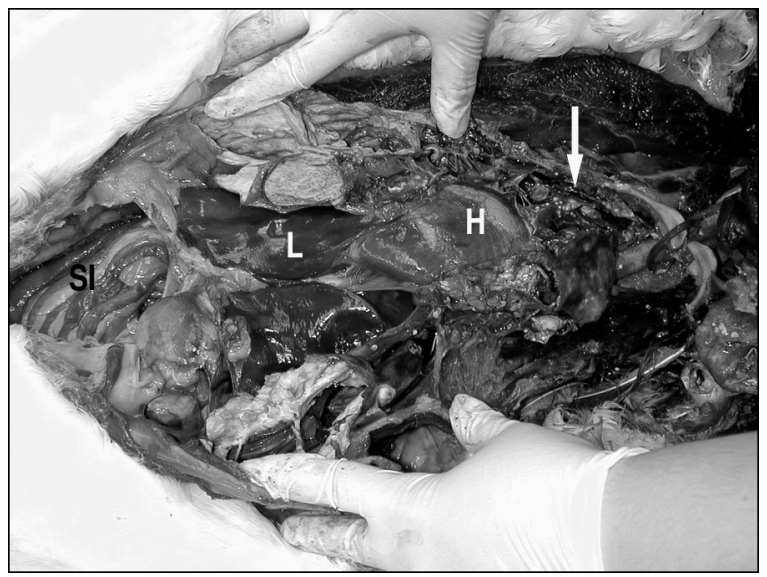

Figure 4. An adult trumpeter swan that died with lesions consistent with aspergillosis. Bilateral yellow, fibrinous casts fill the cranial and caudal thoracic air sacs (between both thumbs and fingers). Fungal lesions are also present in the intraclavicular air sac (arrow). The heart $(\mathrm{H})$, liver $(\mathrm{L})$, and small intestines $(\mathrm{SI})$ are visible. 
Table 2. Severity of fungal lesions by sex, age, and lead exposure in 64 swans with aspergillosis. Swans with aspergillosis were part of a larger group of swans $(\mathrm{N}=400)$ that were submitted for necropsy in Washington State during a 2-year period (2000-02).

\begin{tabular}{|c|c|c|c|c|c|}
\hline & $\begin{array}{l}\text { Swans with } \\
\text { mild } \\
\text { aspergillosis } \\
(\mathrm{n}=13)\end{array}$ & $\begin{array}{l}\text { Swans with } \\
\text { severe } \\
\text { aspergillosis } \\
(\mathrm{n}=51)\end{array}$ & $\begin{array}{l}\text { All swans } \\
\text { with } \\
\text { aspergillosis } \\
(\mathrm{n}=64)\end{array}$ & $\begin{array}{l}\text { All swans } \\
\text { without } \\
\text { aspergillosis } \\
(\mathrm{n}=336)\end{array}$ & $\begin{array}{c}\text { Total } \\
\text { swans } \\
(\mathrm{N}=400)\end{array}$ \\
\hline \multicolumn{6}{|l|}{$\operatorname{Sex}^{b}$} \\
\hline Male & 9 & 33 & 42 & 164 & 206 \\
\hline Female & 4 & 16 & 20 & 164 & 184 \\
\hline \multicolumn{6}{|l|}{ Age } \\
\hline Adult/subadult & 12 & 32 & 44 & 274 & 318 \\
\hline Juvenile $^{\mathrm{d}}$ & 1 & 19 & 20 & 62 & 82 \\
\hline \multicolumn{6}{|l|}{ Lead exposure } \\
\hline $\begin{array}{l}\text { Not lead poisoned }(<8 \text { ppm dry } \\
\text { weight liver lead) }\end{array}$ & 0 & $27^{e}$ & 27 & 51 & 78 \\
\hline $\begin{array}{l}\text { Lead poisoned }(\geq 8 \text { ppm dry } \\
\text { weight liver lead) }\end{array}$ & 13 & 24 & 37 & 285 & 322 \\
\hline \multicolumn{6}{|c|}{$\begin{array}{l}\text { a Includes lead poisoning, trauma, and other or unknown causes of death. } \\
\text { b Sex was missing for } 2 \text { swans with severe aspergillosis and } 8 \text { swans without aspergillosis. } \\
\text { c Males were more likely than females to have aspergillosis }(P=.015) \text {. } \\
\text { d Juveniles were more likely than adult and subadult swans to have aspergillosis }(P=.02) \text {. } \\
{ }^{\mathrm{e}} \text { Includes } 2 \text { swans in which liver lead levels were not available. } \\
{ }^{\mathrm{f}} \text { Combined clinical and subclinical cases of lead poisoning. All swans had clinical lead poisoning ( } \geq 20 \text { ppm dry weight liver lead) } \\
\text { except for } 10 \text { swans with subclinical lead poisoning }(8-19.9 \text { ppm dry weight liver lead), including } 1 \text { swan with mild aspergillosis, } \\
3 \text { swans with severe aspergillosis, and } 6 \text { swans without aspergillosis. }\end{array}$} \\
\hline
\end{tabular}

A description of pathologic lesions associated with lead poisoning and other causes of mortality will be reported elsewhere.

Thirteen birds (all trumpeter swans) had mild aspergillosis and 51 swans (trumpeter, $\mathrm{n}=49$; tundra, $\mathrm{n}=2$ ) had severe infections (Table 2). Overall, males $(n=42)$ were twice as likely as females ( $=20)$ to have fungal lesions (OR, $2.1 ; 95 \% \mathrm{CI}, 1.1-$ $3.9 ; P=.015$; no sex was reported for 2 birds). No significant difference was found between males and females in severity of infection (mild or severe). Juvenile swans were twice as likely as subadult and adult swans to have aspergillosis (OR, 2.0; 95\% CI, 1.1-3.8; $P=.02$ ) (Table 2). Juvenile swans were also more likely than adult and subadult swans to have severe versus mild aspergillosis (OR, 7.1; 95\% CI, 0.9-59.2; $P=.042$ ). However, juvenile male and female swans were no more likely to develop aspergillosis than adult and subadult male and female swans, respectively.

All 13 swans with mild infections had high lead levels in liver (1 subclinical and 12 clinical cases). Of the 51 swans with severe aspergillosis, 24 had high levels of lead in liver tissue (3 subclinical and 21 clinical cases). High lead levels (combined subclinical and clinical cases) were found in 29 adult and subadult swans compared with 8 juvenile swans. Although there were nearly $30 \%$ more birds with concurrent aspergillosis and lead exposure, compared with birds with aspergillosis only, when these groups were compared with the larger group of noninfected swans, lead exposure was not a risk factor for the development of aspergillosis. In fact, swans with lead poisoning were $75 \%$ less likely than swans without lead poisoning to have fungal lesions (OR, 0.25; 95\% CI, 0.131-0.46; $P<.001$ ). Non-lead-poisoned swans with aspergillosis were significantly more likely than lead-poisoned swans to develop severe versus mild infection $(P<.001)$.

Fungal lesions were widely distributed throughout the respiratory system in infected birds, including the trachea, lungs, and air sacs (Table 1). Gross lesions were confined to a single area (trachea, lungs, or air sac) in all birds with mild aspergillosis but were widely distributed to multiple areas in two thirds (34 of 50) of swans with severe aspergillosis. Severe tracheal occlusion of 1 or both loops of the trachea within the keel was reported in 5 birds (all subadult or adult trumpeter swans; $n=4$ males, $n$ $=1$ female). Air sac lesions (alone or in combination with lesions in other locations) were present in 44 swans; lung lesions were present in 35 swans; and tracheal lesions were present in 30 swans. 


\section{Discussion}

Over a 2-year period, aspergillosis was diagnosed in $16 \%$ of 400 trumpeter and tundra swans submitted for necropsy in northwestern Washington State. In this population, all fungal lesions were confined to the respiratory system, and multiple sites (lungs, trachea, and air sacs) were involved in $68 \%$ of swans with severe aspergillosis. Male swans were twice as likely as females and juvenile swans were twice as likely as adult and subadult swans to have fungal disease. Surprisingly, lead poisoning was not a risk factor for concurrent aspergillosis; in fact, lead-poisoned swans were less likely than non-leadpoisoned swans to have aspergillosis. It is likely that most lead-poisoned birds died acutely or subacutely before aspergillosis infections could become established in these compromised birds. Birds with mild aspergillosis and concurrent lead poisoning were unlikely to have had clinical respiratory disease, and we assumed that the infection probably did not contribute to the bird's death. However, if these birds had not died from another cause (eg, lead poisoning), the mild aspergillosis would likely have progressed to severe disease. Birds with severe infections most likely had clinical respiratory disease that contributed to their deaths. The actual cause of death in birds with concurrent aspergillosis and lead poisoning could not be determined retrospectively because no antemortem clinical information was available.

One potential weakness of this study was the lack of microbiologic or histopathologic confirmation of aspergillosis. Cytologic examination of selected lesions demonstrated fungal hyphae, but the specific etiologic agent was not confirmed as Aspergillus species nor specifically identified. Cultures were not done because of sampling costs, and histopathologic examinations were not done because of freezing artifacts and variable postmortem changes found in the carcasses.

Birds with aspergillosis infections typically do not show clinical signs of illness until the disease is in advanced stages. ${ }^{111}$ Clinical signs of aspergillosis can be nonspecific or specific, depending on the location and extent of the lesions. Clinical signs can include dyspnea, tail bobbing, exercise intolerance, and changes or cessation of vocalization, as well as other nonspecific signs of illness such as weakness, anorexia, and weight loss. ${ }^{19,20}$ Unfortunately, antemortem diagnosis of avian aspergillosis can be very challenging because none of the available tests are highly sensitive or specific. A battery of diagnostic tests can be used to arrive at a diagnosis, including hematologic testing, serum protein electrophoresis, aspergillus enzyme-linked immunosorbent assay (ELISA), survey radiographs, endoscopy, and fungal culture and isolation.,.$^{2,19}$

Aspergillosis typically occurs in 3 forms: acute/ disseminated, chronic/disseminated, and chronic/localized. ${ }^{2,19,20}$ Lack of antemortem information related to clinical signs and progression of illness prevented us from categorizing the birds in this study into 1 of the 3 forms. The acute/disseminated form typically occurs in birds that are immune suppressed or incompetent or in birds that inhale large numbers of spores. Respiratory disease and death are rapid. The chronic/disseminated form is reportedly the most common. In this form, the lungs, trachea, or air sacs are extensively infiltrated with fungal organisms, eventually leading to clinical disease, respiratory obstruction, and death. Numerous factors can affect the clinical expression of chronic/disseminated disease, including immune function, concurrent disease, stress, and spore exposure. The chronic/localized form of aspergillosis is typically isolated to the trachea, syrinx, or air sacs, and lesions are usually not clinically significant.

Fungal lesions are most common in the syrinx and cranial portions of the abdominal air sacs. ${ }^{2}$ In one study, $20 \%$ of psittacine birds with aspergillosis had histologic lesions in the trachea, although it was not clear that aspergillosis was the cause of death in all birds examined. ${ }^{21}$ By comparison, $48 \%$ of the swans with aspergillosis in this study had tracheal lesions. One possible explanation for the increased percentage of tracheal lesions in swans is the complex anatomy of the trumpeter swan trachea (Fig 5)..$^{22}$ In trumpeter swans, a caudal and a dorsal loop form two $180^{\circ}$ curves in the section of trachea embedded within the keel. A third loop is formed upon exiting the keel and curving toward the syrinx, bronchi, and lungs. Tundra swans have a similar tracheal arrangement embedded within the keel except for the absence of the dorsal extension. The increased tracheal length combined with the numerous loops in the trachea of the trumpeter swan may alter airflow and allow fungal spores to settle out in the loops or at the narrowed syrinx. Juvenile trumpeter swans have a short extension of the trachea embedded in the keel, and as they mature into adults, the tracheal length and width of loops increases within the keel, ${ }^{22}$ possibly predisposing mature birds to more severe tracheal lesions. The tracheal occlusion with aspergillosis we found in 5 trumpeter swans was similar to that described in a report of tracheal occlusion in 1 of 5 trumpeter swans diagnosed with aspergillosis. ${ }^{19}$

Healthy adult birds with normal immune function probably do not develop aspergillosis except when 


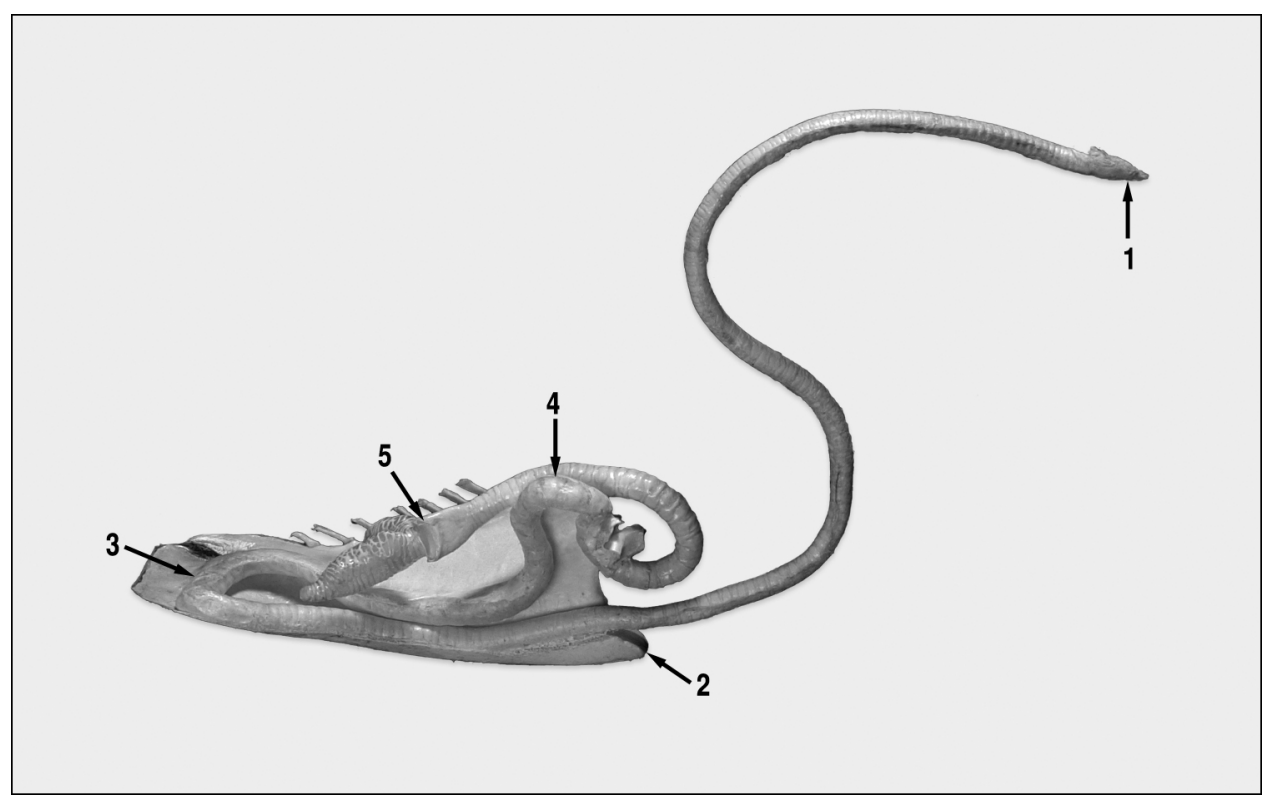

Figure 5. The trachea of an adult trumpeter swan, with a cut-away view of the trachea within the keel, demonstrating the extensive portion of the trachea embedded within the keel. 1) Proximal trachea originating in the oral cavity; 2) cranial-ventral portion of the keel; 3) caudal loop of trachea embedded within the keel; 4) dorsal loop of trachea embedded within the keel; 5) location of the syrinx, just cranial to the large, bilateral syringeal bullae (cut off at the junction of the primary bronchi. (Photo courtesy of JE Smallwood.)

exposed to overwhelming numbers of spores. Birds with compromised or immature immune function may be at greater risk for developing aspergillosis, including immature birds, birds with concurrent illness or injuries, or birds that are stressed by captivity or other environmental changes., ${ }^{2,19,21}$ In this study, immaturity (juvenile age category) was associated with aspergillosis compared with subadult and adult birds. Age classes of birds with lead poisoning or aspergillosis were not reported in other studies of swan mortality. ${ }^{12,13}$ However, in one report of the diagnosis and treatment of aspergillosis in trumpeter swans, 4 of 5 infected swans were juveniles and the fifth swan was a 1.5-year-old subadult. ${ }^{19}$ Research in other species has also shown that immature animals have reduced immune function and may be more susceptible to disease..$^{23-25}$ Additionally, research in poultry has examined methods to accelerate the development of the chick's immune system in an attempt to reduce mortality rates. ${ }^{26}$

Because no information was known about feeding habits and locations of the birds in this study, the sources of aspergillosis infection in these birds could not be determined. Environmental sources such as moldy food, field corn, or other organic material are likely. ${ }^{12}$ The higher proportion of males compared with female swans that were infected with aspergillosis was an unexpected finding, al- though there were similar findings in another report in which 4 of 5 swans that died of aspergillosis were males. ${ }^{19}$ Additionally, in a retrospective study of aspergillosis in psittacine birds, $71 \%$ of the infected birds were males. ${ }^{21}$ Adult swans form lifetime pair bonds and bonded pairs stay together year round, including during the winter season off the breeding territories. ${ }^{18}$ Juvenile offspring stay with their parents through their first winter after hatching, including fall and spring migration. Winter feeding strategies for swans of different ages and genders are similar, and one would expect equal exposure to Aspergillus spores during feeding. ${ }^{12,18}$ Possibly, the immune system of male swans is more compromised than that of female swans during the winter months. However, determining immune competency prospectively or retrospectively would be very difficult, if not impossible, in these birds.

The proportion of swans with aspergillosis in this study was similar to that reported by others. ${ }^{12-13}$ In 2 other studies of swan mortality, lead poisoning was the leading cause of mortality, followed by aspergillosis and trauma. In another study of trumpeter swans, a lower proportionate mortality of $2 \%$ aspergillosis was reported, but lead poisoning was still the most common cause of mortality. ${ }^{27}$ Whether or not birds with aspergillosis had concurrent lead poisoning was not reported in these studies. ${ }^{12-13,27}$ In our study, although $58 \%$ of the birds with aspergil- 
losis also had lead poisoning, we found that leadpoisoned swans were significantly less likely to have aspergillosis than non-lead-poisoned swans. This was an unexpected finding, as numerous studies have shown that lead exposure can alter immune function and increase susceptibility to disease. ${ }^{28-31}$ In a study in mallard ducks, birds given lead shot had reduced antibody production after exposure to sheep red-blood cells. ${ }^{32}$ Although we were unable to measure antemortem immune function in any of the birds in this study, lead-poisoned swans may have been immune compromised. However, leadpoisoned swans most likely died too quickly for reduced immune function to play a role in the development of aspergillosis.

In the study by Astorga et al, ${ }^{14}$ a $0.9 \%-2.5 \%$ seroprevalence for aspergillosis in 3 species of waterfowl was reported. The population studied was apparently healthy (no clinical signs or disease problems were reported), age ranges were not reported, and blood lead levels were not measured. Diagnosis of aspergillosis was by immunodiffusion that detected antibodies to A fumigatus. While A fumigatus is the most common cause of aspergillosis, it is not the only etiologic agent. Additionally, antibody detection determines exposure but does not necessarily prove that a bird is currently infected. Immunodiffusion may not detect antibodies in an animal that does not mount an appropriate immune response. In a recent study, the use of an indirect ELISA for detecting serum antibodies to A. fumigatus was examined in captive penguins. ${ }^{33} \mathrm{Al}-$ though $93 \%$ of the samples were seropositive, there was no correlation with clinical disease, and the serologic results varied between species sampled. Whether the results of serologic surveys using immunodiffusion or indirect ELISA to detect antibodies can be compared with the results of necropsy or culture is questionable. Antemortem diagnosis of aspergillosis is difficult, and fungal culture, histopathologic examination, or both must be done to confirm an active infection. ${ }^{34}$ Recent research in humans has examined the use of antigen detection (Aspergillus galactomannan) in serum for antemortem diagnosis of invasive aspergillosis. ${ }^{35}$ In that study, the ELISA used to detect galactomannan provided a sensitivity of $91 \%$ and a specificity of $94 \%$. Additionally, a study in 2 species of waterfowl found that the detection of an Aspergillus species antigen had a high early predictive value for invasive aspergillosis. ${ }^{36}$ Future research may examine Aspergillus antibody titers based on immunodiffusion or ELISA and serum antigen levels in birds experimentally exposed to lead, with confirmation of in- fection based on fungal culture and histopathologic examination.

During the 2 years of our study, at least 232 other swan deaths were documented, including swan carcasses collected for necropsy in Canada, those too scavenged by predators for useful necropsy, and those submitted to other agencies for scientific purposes. ${ }^{37}$ Our study started 1 year after at least 87 swans died in western Washington State during the winter of 1999-2000 (M. Jordan, unpublished data, February 2001). Some of those that were submitted for necropsy were lead poisoned, but a collective effort to document individual causes of mortality in this group of swans was not done, nor was the number of aspergillosis cases documented. Before 1999, Wilson et $\mathrm{al}^{27}$ reported mortality of 186 trumpeter swans collected over an 18-year-period in British Columbia, with 42 swans documented as the single highest number in 1 year. Lagerquist et $\mathrm{al}^{12}$ reported mortality of 136 trumpeter and tundra swans collected between 1986 and 1992 in Washington State, with an annual high of 27 swan mortalities documented in 1991. Trumpeter and tundra swans wintering in Washington State and British Columbia are part of the Pacific Coast population and primarily forage on agricultural fields. ${ }^{38,39}$ Aerial population surveys are done every 5 years in the US. An aerial survey conducted during the summer of 2000 in Alaska documented over 17000 trumpeter swans, representing a $624 \%$ increase in this population since surveys were first conducted in $1968 .^{40}$ Winter surveys conducted on the Fraser River Delta and lower valley in southwestern British Columbia, Canada (areas just across the border, where swan carcasses were also recovered during our study period), documented 2411 birds in 1998, representing an increase of 539\% since surveys started in 1987. ${ }^{38}$ Midwinter population estimates of trumpeter swans in western Washington State in 2000-01 and 200102 were estimated at 3605 and 4206 swans, respectively (D. Kraege, unpublished data, June 2004). The average annual trumpeter swan mortality rate from all causes during this 2-year period was approximately $5 \%$. The annual estimated trumpeter swan mortality rate from aspergillosis $(<0.4 \%)$, while higher than historically documented in swans in this region, is unlikely to impact the population, particularly because juvenile swans were disproportionately affected and less critical to the breeding population. ${ }^{18}$ An international, multiagency investigation into sources of lead shot has been ongoing since 2001, and it is currently unknown whether swan mortalities from lead poisoning will impact this population of swans. ${ }^{41}$ 
Acknowledgments: We thank Martha Jordan and Drs Clare Bonifant, Deena Brenner, Dan Coombs, Sarah Heilman, Jennifer Kishimori, Elizabeth Riggs, and Michelle Rocque, plus numerous other volunteers for assistance with this project. This study was partially funded by The Trumpeter Swan Society, the International Wild Waterfowl Association, and Dr Mel Levine.

\section{References}

1. Aguilar RF, Redig PT. Diagnosis and treatment of avian aspergillosis. In: Kirk RW, ed. Kirk's Current Veterinary Therapy. Philadelphia, PA: WB Saunders; 1995:1294-1299.

2. Degernes LA, Redig P. Diagnosis and treatment of aspergillosis in trumpeter swans. Proc 11th Trumpeter Swan Soc Conf. 1989;159-161.

3. Nakeeb SM, Babus B, Clifton AY Jr. Aspergillosis in the Peruvian penguin (Spheniscus humboldti). J Zoo Anim Med. 1981;12:51-54.

4. Wolff PL, Petrini KR, Kolmstetter C. An outbreak of aspergillosis in crested wood partridges (Rollulus rouloul). J Zoo Wildl Med. 1992;23:108-112.

5. Marks SL, Stauber EH, Ernstrom SB. Aspergillosis in an ostrich. J Am Vet Med Assoc. 1994;204:784785 .

6. Stroud RK, Duncan RM. Aspergillosis in a redcrowned crane. J Am Vet Med Assoc. 1993;183: 1297-1298.

7. Cork SC, Alley MR, Johnstone AC, Stockdale PHG. Aspergillosis and other causes of mortality in the stitchbird in New Zealand. J Wildl Dis. 1999;35:481486.

8. Tsai SS, Park JH, Hirai K, Itakura C. Aspergillosis and candidiasis in psittacine and passeriforme birds with particular reference to nasal lesions. Avian Pathol. 1992;21:699-709.

9. Greenacre CB, Latimer KS, Ritchie BW. Leg paresis in a black palm cockatoo (Probosciger aterrimus) caused by aspergillosis. J Zoo Wildl Med. 1992;23: $122-126$.

10. Carrasco L, Lima JS Jr, Halfen DC, et al. Systemic aspergillosis in an oiled Magellanic penguin (Spheniscus magellanicus). J Vet Med B. 2001;48:551-554.

11. Wobeser GA. Diseases of Wild Waterfowl. 2nd ed. New York, NY: Plenum Press; 1997.

12. Lagerquist JE, Davison M, Foreyt WJ. Lead poisoning and other causes of mortality in trumpeter ( $C y g$ nus buccinator) and tundra (C. columbianus) swans in western Washington. J Wildl Dis. 1994;30:60-64.

13. Degernes LA, Frank RK. Causes of mortality in trumpeter swans (Cygnus buccinator) in Minnesota 1986-1989. Wildfowl. 1991(suppl 1):352-355.

14. Astorga RJ, Cubero MJ, Leon L, et al. Serological survey of infections in waterfowl in the Guadalquivir marshes (Spain). Avian Dis. 1994;38:371-375.

15. Clausen B, Elvestad K, Karlog O. Lead burden in mute swans from Denmark. Nord Vet Med. 1982;34: 83-91.

16. Windingstad RM, Hinds LS III. Lead poisoning in
Canada geese on Plum Island, Massachusetts. $J$ Wildl Dis. 1987;23:438-442.

17. Degernes LA, Frank RK, Freeman ML, Redig PT. Lead poisoning in trumpeter swans. Proc Annu Conf Assoc Avian Vet. 1989;144-155.

18. Mitchell CD. Trumpeter swan (Cygnus buccinator). In: Poole A, Gill F, eds. The Birds of North America. No. 105. Philadelphia, PA: The Academy of Natural Sciences; 1994:1-24.

19. O'Meara DC, Witter JF. Aspergillosis. In: Davis JW, Anderson RC, Karstad L, Trainer DO, eds. Infectious and Parasitic Diseases of Wild Birds. Ames, IA: Iowa State University Press; 1971:153-162.

20. Bauck L. Mycoses. In: Ritchie BW, Harrison GJ, Harrison LR, eds. Avian Medicine: Principles and Applications. Lake Worth, FL: Wingers Publishing; 1994:997-1006.

21. McMillan MC, Petrak ML. Retrospective study of aspergillosis in pet birds. J Assoc Avian Vet. 1989;3: 211-215.

22. Boyd H. Classification. In: Scott P, ed. The Swans. Boston, MA: Houghton Mifflin Co; 1972:17-27.

23. McTaggart C, Yovich JV, Penhale J, Raindal SL. A comparison of foal and adult horse neutrophil function using flow cytometric techniques. Res Vet Sci. 2001;71:73-79.

24. Aitken ID. Immunity to chlamydia. In: Rose ME, Payne LN, Freeman BM, eds. Avian Immunology. Edinburgh, Scotland: Clark Constable Ltd; 1981: 301-312.

25. Parry SH, Porter P. Immunity to Escherichia coli and Salmonella. In: Rose ME, Payne LN, Freeman BM, eds. Avian Immunology. Edinburgh, Scotland: Clark Constable Ltd; 1981:327-348.

26. Klasing KC. Immunomodulation in poultry. In: Davison TF, Morris TR, Payne LN, eds. Poultry Immunology. London, England: Journals Oxford Ltd; 1996:329-342.

27. Wilson LK, Elliott JE, Langelier KM, et al. Lead poisoning of trumpeter swans, Cygnus buccinator, in British Columbia, 1976-1994. Can Field-Nat. 1998; 112:204-211.

28. Knowles SO, Donaldson WE, Andrews JE. Changes in fatty acid composition of lipids from birds, rodents and preschool children exposed to lead. Biol Trace Elem Res. 1998;61:113-125.

29. Kowolenko M, Tracy L, Mudzinski S, Lawrence DA. Effect of lead on macrophage function. J Leukoc Biol. 1988;43:357-364.

30. Knowles SO, Donaldson WE. Lead disrupts eicosanoid metabolism, macrophage function, and disease resistance in birds. Biol Trace Elem Res. 1997;60:1326.

31. Lawrence DA. In vivo and in vitro effects of lead on humoral and cell mediated immunity. Infect Immun. 1981;31:136-143.

32. Trust KA, Miller MW, Ringelman JK, Orme IM. Effects of ingested lead on antibody production in mallards (Anas platyrhynchos). J Wildl Dis. 1990;26: 316-322. 
33. German AC, Shankland GS, Edwards J, Flach EJ. Development of an indirect ELISA for the detection of serum antibodies to Aspergillus fumigatus in captive penguins. Vet Rec. 2002;150:513-518.

34. Forbes NA. Diagnosis of aspergillosis and treatment with itraconazole. Vet Rec. 1992;130:519-520.

35. Sulahian A, Boutboul F, Ribaud P, et al. Value of antigen detection using an enzyme immunoassay in the diagnosis and prediction of invasive aspergillosis in two adult and pediatric hematology units during a 4-year prospective study. Cancer. 2001;91:311-318.

36. Graczyk TK, Cranfield MR, Klein PN. Value of antigen and antibody detection, and blood evaluation parameters in diagnosis of avian invasive aspergillosis. Mycopathologica. 1998;140:121-127.

37. Degernes L, Bowes V, Raverty S, et al. Trumpeter and tundra swan mortality in Washington State, USA and British Columbia, Canada, 2000-2002. In: Weaver DK, Linck MH, Shea RE, eds. $N$ Am Swans 2004;32:13-14.
38. Hawkings JS, Breault A, Boyd S, et al. Trumpeter swan numbers and distribution in western Canada, 1970-2000. Waterbirds 2002;25(special publication $1): 8-21$.

39. Anderson PS. Distribution and habitat selection by wintering trumpeter swans in the lower Skagit Valley, Washington. In: Compton DC, Linck MH, Nelson H, Balcomb JR, eds. Proc 14th Trumpeter Swan Soc Conf. 1993;61-93.

40. Conant B, Hodges JI, Groves DJ, King JG. Census of trumpeter swans on Alaskan nesting habitats, 1968-2000. Waterbirds. 2002;25(special publication 1):3-7.

41. Wilson L, Davison M, Kraege D. Lead poisoning of trumpeter and tundra swans by ingestion of lead shot in Whatcom County, Washington, USA and Sumas Prairie, British Columbia, Canada. In: Weaver DK, Linck MH, Shea RE, eds. N Am Swans 2004;32:1113. 